\title{
Chelate Chrome Use for the Vermiculture
}

\author{
I. Beshkenadze, M. Gogaladze, N. Klarjeishvili, M. Chikaidze, L. Gogua, O. Lomtadze
}

\begin{abstract}
Effect of methionine-containing chelate chrome, having $\mathrm{Cr}(\mathrm{Mt})_{3} \cdot \mathbf{H H}_{2} \mathrm{O}$ formula on the protein mass change of rainworms and on the degree of cocoon reproduction is studied, and the impact of various external stress-factors, namely submerging, substrate quality and toxic doses of chelate chrome on the rainworms is established. For these purposes the experiment was carried out according to the same scheme for four options. Four (one control and three test) groups: with maximum (Max.), normal (Norm.) and minimum (Min.) doses of chelate chrome (in gr.) were composed for all options, each with three repetitions. 5 worms with roughly equal masses were selected for each repetition. Weighing and cocoons' counting were conducted in three stages, on the $21^{\text {st }}, 31^{\text {st }}$ and $41^{\text {st }}$ days since the start of the experiment. In the first option of the experiment throughout the course of the test an increase in rainworms' mass takes place in all groups. Apart from that, in comparison to all test groups the degree of mass increase is high and reaches the maximum in the I test group - 106,19\%. As for the increase in the degree of cocoons' reproduction, it is higher in all test groups compared to the control one and reaches the maximum in the III test group - 142,59\%. On the basis of obtained results the optimum and effective dosage of chelate chrome is established and is $0,0028 \mathrm{gr}$. per $300 \mathrm{gr}$. of.

When studying external stress-factors - submerging (second option) and low-quality substrate (third option), on the basis of carried-out studies it was established that chelate chrome increases the stability of rainworms against different external stress-factors that is expressed in the fact that in all three repetitions of the control group all worms died during submerging and when using a low-quality substrate, while in test groups part of them died. On the basis of experiments conducted regarding the toxicity of chelate chrome towards rainworms (fourth option) we can conclude that they are quite sensitive towards high doses of microelements which is expressed in the fact that worms' death took place in all test groups, while five worms in each repetition of the control group were completely intact. Thus, the rainworms can be successfully used as biotests of microelements' toxicity. This circumstance is very important due to the cheapness and simplicity of the method.
\end{abstract}

Index Terms- Degree of reproduction, Cocoon, Microelement, Rainworm, Substrate, Vermiculture.

Iamze Beshkenadze, Iv. Javakhishvili Tbilisi State University, P.Melikishvili Institute of Physical and Organic Chemistry Tbilisi, Georgia, \#31 A.Politkovskaia str. 0186,

Maia Gogaladze, Iv. Javakhishvili Tbilisi State University, P.Melikishvili Institute of Physical and Organic Chemistry Tbilisi, Georgia, \#31 A.Politkovskaia str. 0186

Nazibrola Klarjeishvili, Iv. Javakhishvili Tbilisi State University, P.Melikishvili Institute of Physical and Organic Chemistry Tbilisi, Georgia, \#31 A.Politkovskaia str. 0186

Marina Chikaidze,Biorational Technologies Research Center (BrTRC), Tbilisi. Georgia \# 8 Iumashevi str. 0151

Lia Gogua, Tbilisi State Medical University Tbilisi, Georgia, \#33Vaja-Pshavela Ave. 0186

Omar Lomtadze, Iv. Javakhishvili Tbilisi State University, P.Melikishvili Institute of Physical and Organic Chemistry Tbilisi, Georgia, \#31 A.Politkovskaia str. 0186

\section{INTRODUCTION}

Highlight Improvement of environmental state and population health is a global problem as of today and it is as topical for the modern mankind as never before [1-8]. In order to solve these problems the production of ecologically safe agricultural products is very important and rainworms can play a crucial role in it [9-18]. At that a high price of rainworms is one of the impeding factors of their use. That's why the study of different factors' effect on the increase of protein mass and the degree of reproduction of rainworms is of great importance [17-18]. Among these factors we focused our attention on the microelement - chrome. It ranks among the vital indispensable elements. Chrome performs a number of important functions in the organism: participates in the functioning of cardiovascular system, fat metabolism, in the adjustment of energy consumption by muscular tissues and has the impact on lipid exchange. The main reason that predetermined the selection of chelate chrome as a research object lies in the fact that it positively impacts the male reproductive system as far as it improves the fertilization ability of spermatozoids [19-29]. In the physiological and biological processes proceeding in a living organism, vital microelements predominantly perform their function in the form of compound coordination (chelate). At that it is established that the degree of microelements' assimilation in the chelate form is far higher (60-70\%) compared to inorganic forms (4-10\%). Taking into account these factors the microelement chrome being in chelate form was selected as a research object.

So, the goal of the experiment is to study the effect of chelate form: a) on the rainworms' mass and degree of reproduction; b) on the various external stress-factors (submerging, low-quality of substrate) and the impact of high-toxicity doses of chrome on the rainworms' mass and degree of reproduction. The new species of earthworm "Georgian new", which is bred in the Macro-Prim LLC company'sbiofarm by the selectionistGuramGejadze were selected for an experiment [30].

\section{COMPUTATIONAL METHOD}

We were unable to find out in the accessible literary sources the researches similar to the study to be conducted, that's why we carried out the experiment according to methodology developed by us, and we used the weighing method - for determination of live weight of worms, and count method - for determination of cocoons' number. The research objects are: rainworms, cocoon, substrate and chelate chrome.

In the test period the following was studied: 
- the dynamics of rainworms' mass change; weighing procedures were conducted in three stages - on the $21^{\text {st }}, 31^{\text {st }}$ and $41^{\text {st }}$ days since the start of the test (the average mass (in grams) for each stage and each group).

- the number of cocoons laid by rainworms apiece (singly) in the each repetition; average quantity of cocoons for each group apiece in the same time interval for each stage

- $\quad$ total mass change (in grams and percentage terms) for all three stages of control and test groups throughout the course of the experiment and average quantity of cocoons apiece and in percentage terms.

- $\quad$ effective and optimum dose of chelate chrome used as test sample for rainworm substrate.

\section{RESULTS AND ANALYSIS}

The joint researches focused on the study of impact of different supplements and external factors on the rainworm's protein mass and degree of reproduction continue with the participation of the laboratory of agrarian chemistry problems of the P.Melikishvili Institute of Physical and Organic Chemistry at the Iv. Javakhishvili Tbilisi State University and research centre "Bioteks". Experiment was conducted according to the same scheme in four options (Table 1).

Table 1

Table 1 Scheme of conducted experiment

\begin{tabular}{|l|l|l|}
\hline Options & Goal of the experiment & Results \\
\hline \multirow{5}{*}{ I } & $\begin{array}{l}\text { a)Impact of chelate chrome on the protein mass } \\
\text { change and degree of cocoons' reproduction }\end{array}$ & $\begin{array}{l}\text { a) Substrate saturation with chelate chrome has the positive } \\
\text { effect on the protein mass change and degree of cocoon } \\
\text { reproduction }\end{array}$ \\
\cline { 2 - 3 } & $\begin{array}{l}\text { b)Establishment of effective and optimum dose of } \\
\text { chelate chrome }\end{array}$ & $\begin{array}{l}\text { b)Effective and optimum dose of chelate chrome is } \\
0,0028 \mathrm{gr} \text {. per 300 gr. of substrate }\end{array}$ \\
\hline II & $\begin{array}{l}\text { Establishment of submerging impact on rainworms } \\
\text { under conditions of substrate saturation with chelate } \\
\text { chrome }\end{array}$ & $\begin{array}{l}\text { Substrate saturation with chelate chrome increases the } \\
\text { rainworms stability against external stress-factor } \\
\text { submerging }\end{array}$ \\
\hline III & $\begin{array}{l}\text { Establishment of impact of low-quality substrate } \\
\text { saturated with chelate chrome on the rainworms }\end{array}$ & $\begin{array}{l}\text { Substrate saturation with chelate chrome increases the } \\
\text { rainworms' stability against the low-quality substrate }\end{array}$ \\
\hline IV & $\begin{array}{l}\text { Establishment of impact of toxic doses of chelate } \\
\text { chrome on the rainworms }\end{array}$ & $\begin{array}{l}\text { Rainworms can be used as biotests for toxic doses of } \\
\text { microelements }\end{array}$ \\
\hline
\end{tabular}

Table 2 Study of the chelate chrome effect on the mass change and degree of reproduction of rainworms

Test sample: $\mathrm{Cr}(\mathrm{Mt})_{3} \cdot 4 \mathrm{H}_{2} \mathrm{O}$

Substrate mass in container: $300 \mathrm{gr}$.

Quantity of rainworms in container: 5 worms

\begin{tabular}{|c|c|c|c|c|c|c|c|c|c|c|c|c|c|c|c|c|c|c|c|c|c|}
\hline \multirow{4}{*}{\multicolumn{2}{|c|}{ 芯 }} & & \multirow{4}{*}{ 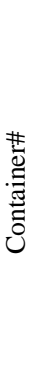 } & \multicolumn{14}{|c|}{ Test stages } & \multirow{2}{*}{\multicolumn{4}{|c|}{ Results }} \\
\hline & & & & \multicolumn{2}{|c|}{ Initial } & \multicolumn{4}{|c|}{ I weighing } & \multicolumn{4}{|c|}{ II weighing } & \multicolumn{4}{|c|}{ III weighing } & & & & \\
\hline & & & & \multirow{2}{*}{ 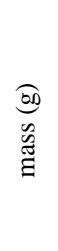 } & \multirow{2}{*}{ 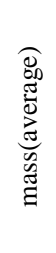 } & \multirow{2}{*}{ 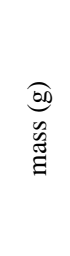 } & \multirow{2}{*}{ 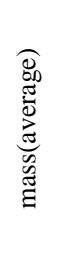 } & \multirow{2}{*}{ 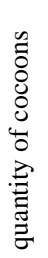 } & \multirow{2}{*}{ 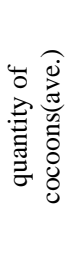 } & \multirow{2}{*}{ 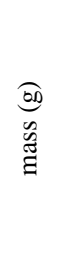 } & \multirow{2}{*}{ 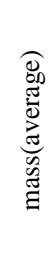 } & \multirow{2}{*}{ 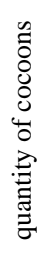 } & \multirow{2}{*}{ 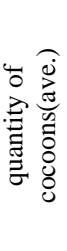 } & \multirow{2}{*}{ 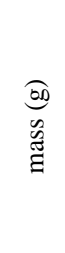 } & \multirow{2}{*}{ 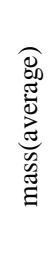 } & \multirow{2}{*}{ 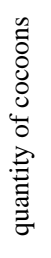 } & \multirow{2}{*}{ 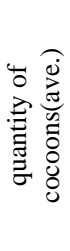 } & \multicolumn{2}{|c|}{$\begin{array}{l}\text { Mass } \\
\text { change }\end{array}$} & \multicolumn{2}{|c|}{$\begin{array}{c}\text { Aver. } \\
\text { quant. of } \\
\text { cocoons }\end{array}$} \\
\hline & & & & & & & & & & & & & & & & & & E्(D & ef & $\frac{0}{\tilde{U}}$ & 8 \\
\hline \multirow{3}{*}{$\begin{array}{l}\bar{O} \\
\stackrel{\Xi}{0} \\
ن\end{array}$} & \multirow{3}{*}{\multicolumn{2}{|c|}{$\stackrel{8}{8}$}} & 1 & 1.80 & \multirow{3}{*}{$\stackrel{+}{n}$} & 5.62 & \multirow{3}{*}{$\hat{\sigma}$} & 10 & \multirow{3}{*}{$\stackrel{8}{\circ}$} & 6.85 & & 29 & & 7.23 & & 29 & & & & & \\
\hline & & & 2 & 1.45 & & 4.50 & & 8 & & 5.56 & $\begin{array}{l}\infty \\
\stackrel{\infty}{n}\end{array}$ & 26 & ठ․ & 5.60 & $\stackrel{\infty}{\circ}$ & 19 & 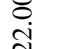 & $\underset{\forall}{\stackrel{\partial}{+}}$ & 8 & $\stackrel{\infty}{-}$ & 8 \\
\hline & & & 3 & 1.36 & & 4.68 & & 3 & & 5.52 & & 20 & & 5.10 & & 18 & & & & & \\
\hline & & & 4 & 2.39 & & 6.39 & & 15 & & 7.23 & & 30 & & 7.59 & & 31 & & & & & \\
\hline$\stackrel{.}{\Xi}$ & $\S$ & & 5 & 2.10 & 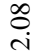 & 5.18 & $\begin{array}{l}\stackrel{P}{r} \\
i n\end{array}$ & 13 & & 6.21 & $\stackrel{2}{0}$ & 30 & $\widehat{6}$ & 6.14 & $\stackrel{n}{\infty}$ & 27 & $\underset{0}{0}$ & $\stackrel{\forall}{\sim}$ & ச் & $\stackrel{r}{+}$ & ন্d \\
\hline & & & 6 & 1.75 & & 5.53 & & 7 & & 6.72 & & 26 & & 6.82 & & 23 & & & & & \\
\hline & & & 7 & 1.97 & & 5.21 & & 13 & & 5.74 & & 16 & & 5.99 & & 29 & & & & & \\
\hline E్ & $\Theta$ & $\overline{8}$ & 8 & 1.92 & $\stackrel{n}{\mathfrak{n}}$ & 5.79 & ?ִ & 10 & $\stackrel{6}{6}$ & 6.54 & กֶ & 34 & $\underset{\infty}{0}$ & 6.43 & $\stackrel{\infty}{\infty}$ & 20 & $\begin{array}{l}6 \\
\dot{\sigma}\end{array}$ & $\stackrel{7}{\square}$ & כ̄ & $\vec{i}$ & $\stackrel{\infty}{i}$ \\
\hline 4 & & 0 & 9 & 1.95 & & 5.08 & & 18 & & 6.32 & & 34 & & 6.16 & & 25 & & & & & \\
\hline & & & 10 & 2.17 & & 5.52 & & 21 & & 6.62 & & 28 & & 6.58 & & 23 & & & & & \\
\hline 范 & 国 & ชิ & 11 & 2.22 & $\frac{n}{i}$ & 6.14 & ñ & 18 & $\stackrel{m}{\stackrel{n}{n}}$ & 7.28 & $\underset{0}{0}$ & 37 & $\underset{8}{8}$ & 7.53 & $\begin{array}{l}0 \\
\infty \\
0 \\
0\end{array}$ & 30 & $\hat{\sigma}$ & 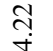 & ஸे & $\begin{array}{l}\hat{b} \\
\dot{n}\end{array}$ & $\stackrel{\sim}{\sim}$ \\
\hline & & 0 & 12 & 2.06 & & 5.10 & & 13 & & 6.07 & & 37 & & 6.46 & & 24 & & & & & \\
\hline
\end{tabular}


In the first option the observation was conducted: a) in the direction of study of rainworm's mass change and the degree of reproduction under the influence of chelate chrome added to the substrate and $b$ ) towards the establishment of effective and optimum dose of chelate chrome. With this end we tested four groups in total, each one with three repetitions: the substrate of all three repetitions of the control group was moistened by ordinary water; samples of the I test group with the aqueous solution containing minimum $(0,0007$ gr.) dose of chelate chrome; of the II test group - with the aqueous solution containing normal $(0,0014$ gr.) dose of chelate chrome and of the III test group - with the aqueous solution containing maximum $(0,0028$ gr.) dose of chelate chrome. For each repetition of each group we selected 5 worms with roughly equal mass. First weighing and cocoon counting were made on the $21^{\text {st }}$ day from the beginning of experiment, while the second and third procedures - on the $31^{\text {st }}$ and $41^{\text {st }}$ days, respectively. During all three weighing for each group we counted the average mass in grams, average quantity of cocoons apiece. After completion of the experiment the change of average mass of all stages was calculated in grams and in percentage terms for the control and all three test groups; and cocoon's quantity apiece and in percentage terms (Table 2).

\section{Table 2}

As seen from the table, at the beginning of the experiment a maximum mass increase by 3.39 gr. $(4,93-1,54)$ takes place in the control group at the I stage; at the II stage it equals to $1.05 \mathrm{gr}(5.98-4.93)$, while there is no mass change at the III stage. In parallel with such mass change in the control group an average quantity of cocoons first increased from 7.0 to 25.0 at the II stage and then reduced to 22.0 at the III stage.

In the Itest group, to which a minimum dose of chelate chrome was added, in between I and III stages a slight, yet still, a mass change took place in comparison to the control group. As for the cocoons' quantity (apiece) according to the stages, it was changed as follows: I-11.67; II-28.67; III -27.00 .

In the II test group, to which a normal dose of chelate chrome was added, mass increase at the I stage is $3.41 \mathrm{gr}$ (5.36-1.95), at the II - 0.84gr.(6.2-5.36), while at the III 0.60 gr.(6.80-6.20). In parallel with such nature of mass change the quantity of cocoons at the I stage is equal to 13.67 , at the II -28.00 , while at the III -24.67 .

In the III group containing a maximum dose of chelate chrome, the worms' mass change is of the following nature: at the I stage it increases by 3.44gr.(5.59-2.15), at the II - by $1.07 \mathrm{gr}(6.66-5.59)$, while at the III - by 0.2 gr.(6.86-6.66). In parallel with such nature of mass change the quantity of cocoons (apiece) at the I stage is equal to 17.33 , at the II 34.00 , while at the III -25.67 .

Throughout the experiment for each group and for all three stages in total the mass change took place on average in all groups and if we take it conventionally as $100 \%$ (4.09 gr), then in the I test group it will be $106.19 \%(4.34 \mathrm{gr}$.); in the II-101.96\%(4.17gr.), while in the III test group $103.12 \%$ (4.22gr.); similarly the total change in the degree of cocoons' reproduction is of the following nature: control group $100 \%$ (18 pieces), I test group $124.70 \%$ (22.45 pieces), II $-122.85 \%(22.11$ pieces $)$ and III test group -

\section{$142.59 \%$ (25.67 pieces).}

The goal of our research was also the study of impact of the following external stress-factors:flooding (second option of the experiment), low-quality substrate (third option) and high, so-called toxic doses of chelate chrome (fourth option) - on the rainworms (under conditions of substrate saturation with chelate chrome). For this purpose we set up an experiment precisely according to the above described scheme and undertook the containers' submerging for the second option. During the first weighing we got the following picture on the $21^{\text {st }}$ day: all five rainworms died in the control group, while in the test groups their partial death $(1 ; 2$ or maximum 3 worms) took place.

When conducting the same experiment under conditions of low-quality substrate (third option) that was expressed in the fact that substrate was moldy and saturated with different pathogenic organisms, the similar picture was obtained: all worms died in the control containers, while in test containers a partial death of worms occurred.

In the fourth option of the experiment we saturated the substrates of the test groups with high-toxicity doses of chelate chrome. When placing worms in containers all five worms of the control group were easily located, while in the test groups, where the substrate was saturated with 4 times bigger quantity of chelate chrome compared to minimum, normal and maximum doses of the main scheme, we faced difficulties when placing worms in containers, because they slid on the substrate surface and tried to run away. On the $21^{\text {st }}$ day when inspecting the containers it turned out that all worms of control group were intact and they started to lay the cocoons, while no worms were found in the containers of the test groups, they either ran away or died.

\section{CONCLUSION}

On the basis of analysis of results obtained after conducted experiments we can make a following conclusion: in the first option of the experiment throughout the course of the test in all groups the rainworms' mass increase takes place. At that, the mass increase degree is high compared to the control group and reaches the maximum in I test group - 106,19\%. As for the increase in degree of cocoons' reproduction it is higher in all test groups in comparison with control group and reaches maximum in III test group $-142,59 \%$. On the basis of analysis of obtained results we can establish the optimum and effective dose of chelate chrome and it equals to 0,0028 gr. per 300 gr. of substrate.

Thus, balancing of rainworm substrate using chelate chrome has a positive impact on the rainworms' mass increase and substantially improves the degree of cocoons' reproduction that can be explained by biological activity of microelement - chrome, in particular, its effect on reproductive system that is expressed in improvement of fertilization ability of spermatozoids. We think that the obtained results are of great importance for that direction of vermiculture, where a protein mass is used for balancing the combined feed of agricultural animals and birds as a vitamin-protein, high-quality, concentrated supplement.

On the basis of conducted researches it was also established that a chelate chrome increases the rainworms' stability against different external stress-factors (such as submerging, low-quality substrate). Based on the 
experiments related to the toxicity of chelate chrome towards rainworms one may say that they are quite sensitive towards high doses of microelements and rainworms can be successfully used as biotests of microelements' toxicity. This circumstance is very important due to cheapness and simplicity of the method.

\section{REFERENCES}

[1] Role of microelements to keep in balance mineral nutrition of agricultural http://www.bhz.kosnet.ru/Rus/Stat/St_2010_03_Chenonogov.html;

[2] "Microelements in the Agriculture" / Edited by S.YU.Buligina -Dnepropetrovsk "Dneprkniga 2003, p.80(in Russian)

[3] G.O. Karapetyan, K. G. KArapetyan."Mineral Fertilizers of XXI century in light of the ecology problems"Schientific-Technical Bulletin, Sankt Petersburg State Technical University 2000, 1, p.19

[4] N.A.Dobrinina, "Biological chemistry" Lomonosov Moscow State University, Moscow, 2007.p.361(in Russian)

[5] S.Bulygin, K.Demishev, V.Doroninaet. al. "Microorganisms in agriculture", Dnepropetrovsk, "Sych" 2007, p.100.(in Russian)

[6] G.Loginov "Effect of metal chelates with amino acids and protein hydrolysates on the productive functions and metabolic processes in animal body" Doctor's thesis, Kazanj, 2005, 359 p.

[7] I.Beshkenadze, M.Gogaladze et al. „Chelate phytoregulator” U 1746Sakpatenti2011.

[8] I.Beshkenadze, A.Chagelishvili, M.Gogaladze et al."Heteronuclearcitrates containing admix for Poultry Feeding" U1887Sakpatenti 2014.

[9] "Vederstad"https://www.vaderstad.com/ru/know-how/../dohzdevye-c hervi/

[10] AnimalRegister.net http://animalregister.net/d/dozhdevyie-chervi.html

[11] I.N.Titov, V.M.Usoev"Bulletin" of Tomsk State University.Biology. Issue 2012cyberleninka.ru/.../vermikultura-kak-vozobnovlyaemyy-istochni k-zhivotnogo-belka-iz-organicheskih-othodov.

[12] Earth Angels - Health and Well being to you. "Vermitechnology for Developing Countries" - ISWVT 16-18 November, 2005, Los-Banios, Laguna, Philippines

[13] I.N.Titov"Processing the organic fraction of wastes" Bulletin of Tomsk State University. Biology ISSN (print) 1998-8591, 2008, 8.pp.18-25 (in Russian)

[14] C.A.Edwards, A.A.Niederer, N.Q.Arancon, R.N.Sherman"The production of earthworm protein for animal feed from organic wastes" Vermiculture Technology: Earthworms, Organic Wastes, and Environmental Management ed. by. CRS Press, Taylor and Francis Group, 2011, pp. 323-334

[15] S.Zhenjun. "Vermiculture\&Vermiprotein" Tomsk State University Journal of Biology.2012, \# 2 (18).pp. 74-80

[16] Rainworm,https://opinion.inquirer.net/7208/culturing-worms-to-enric h-the-earth

[17] I.Beshkenadze, V.Tsitsishvili, M.Gogaladze et al. "The use of zinc chelate of vermicultivation"U1956 Sakpatenti 2016.

[18] I.Beshkenadze, N.Zazashvili, M.Gogaladze, N.Klarjeishvili, M.Chikaidze, O.Lomtadze. "Effect of the Concentrate "Rumifos" on the Mass and the Degree of Reproduction of Rain Worms". AnnalsofAgrarianScience2019, 17, pp.12-19

[19] Biologically active food supplements https://www.rlsnet.ru/books book id 2 page 274. htm

[20] A.Shvelashvili, I.Beshkenadze, et al. "Amino Acid-Containing Bio-Coordination Compounds and Study of Their Biological Activity" Proceedings of the Academy of Sciences of Georgia 2000 \#3-4, vil.26. pp.24-30

[21] I.Beshkenadze, M.Gogaladze, I.Lomtadze. et al. "Minerals and Glutamininic acid Containing biologically active Foodadditive" II International Scientific Conference, 2010, 3-5 September, pp.56-59. Georgia, Batumi

[22] R.A. Anderson "Chromium as an essential nutrient: http://www.chromiumasoc.com/ publications/crfile6sep99.htm. Accessed 30 January 2004

[23] D.G.Barceloux"Chromium" Clinical Toxicology, 1999, v. 37, \#2, pp. 173-194.

[24] "Chromium Toxicity" U.S. Department of Health and Human Services. Agency for Toxic Substances and Disease Registry, Division of Toxicology and Environmental Medicine, http://www.atsdr.cdc.gov/csem/chromium/docs/chromium.pdf.

December 18, 2011
[25] "Scientific Opinion on Dietary Reference Values for chromium" EFSA Journal, 2014\#12, pp.10-27.

[26] J.B.Vincent"Recent advances in the nutritional biochemistry of trivalent chromium" Proceedings of the Nutrition Society, 2007, v.63, \#1, pp.41-47.

[27] M.Y. Thor, L.Harnack, D.King,B.Jasthi, J. Pettit "Evaluation of the comprehensiveness and reliability of the chromium composition of foods in the literature" J. Food Compost. Anal., 2011, v.24, \#8, pp.147-1152.

[28] K.L.Kamerud,K.A.Hobbie,K.A.Anderson"Stainless Steel Leaches Nickel and Chromium into Foods During Cooking" J. Agric. Food Chem., 2013, v.61, \#39, pp.9495-9501.

[29] G.W.Mathison,D.F.Engstrom"Chromium and protein supplement for growing-finishing beef steers fed barley-based diets" Canadian J. Animal Sci., 1995, v., pp.549-558.

[30] G.Gejadze Rain Worm“Georgian New” \#167 Sakpatenti, 2017 